\title{
Modelling fire-fighter responses to exercise and asymmetric infrared radiation using a dynamic multi-mode model of human physiology and results from the Sweating Agile thermal Manikin
}

\begin{abstract}
In this study, predicted dynamic physiological responses are compared with wear trials results for firefighter suits: impermeable (A), semi-permeable (B) and permeable $(\mathrm{C})$, and underwear. Wear trials consisted of three rest phases and two moderate work phases, with a frontal infrared (IR) radiation exposure of $500 \mathrm{~W} / \mathrm{m}^{2}$ for the last $15 \mathrm{~min}$ of each work phase. Simulations were performed by detailed modelling of the experimental boundary conditions, including the inhomogeneous IR radiation combined with clothing properties for still and walking conditions measured using the Sweating Agile thermal Manikin. Accounting for the effect of sweat gland activity suppression with increased skin wettedness, the predicted total moisture loss was insignificantly different $(P<0.05)$ from the wear trial value for suits $\mathrm{B}$ and $\mathrm{C}$ but was $37 \%$ too high for suit $\mathrm{A}$. Predicted evolution of core, mean skin and local skin temperatures agreed well with the wear trial results for all clothing. Root mean square deviations ranged from $0.11^{\circ} \mathrm{C}$ to $0.26^{\circ} \mathrm{C}$ for core temperatures and from $0.28^{\circ} \mathrm{C}$ to $0.38^{\circ} \mathrm{C}$ for mean skin temperatures, which where typically lower than the experimental error. Transient thermodynamic processes occurring within suit A may account for the delayed/reduced fall in core temperature following exercise.
\end{abstract}

Keywords Body temperatures - Simulation · Sweating $\cdot$ Thermal manikin $\cdot$ Wear trials

M. G. M. Richards ( $₫)$

Swiss Federal Laboratories for Materials Testing and Research (EMPA), 9014 St. Gallen, Switzerland

E-mail: mark.richards@empa.ch

D. Fiala

Institute of Energy and Sustainable Development, De Montfort University, Scraptoft Campus, Leicester, LE7 9SU, UK

\section{Introduction}

Humans respond to their environment dynamically, with a thermoregulatory system which usually can maintain the core temperature within a narrow range. Clothing tends to inhibit the transport of body heat and moisture away from the body or external radiation to the body (Lotens 1993). Sweating thermal manikins, such as the Sweating Agile thermal Manikin (SAM), enable both the thermal and moisture transport through clothing systems to be studied (Richards and Mattle 2001; Fan and Chen 2002). SAM provides information on clothing properties and local heat transfer coefficients for a variety of thermophysiological and repetitive body movement conditions. These data can be used in conjunction with detailed simulation models to predict human responses to transient environmental and personal conditions more realistically.

Recently the Institute of Energy and Sustainable Development (IESD) has developed a dynamic model of human heat transfer (Fiala et al. 1999, 2001) which represents one of the most advanced multi-segmental models in this field (Tikuisis 2000). This model will be referred to henceforth as the IESD model. Human wear trial results for firefighter clothing (Richards 2000) have been compared with results from SAM (Richards et al. 2003). However, no direct comparison is possible without using a physiological model. This study compares these wear trial results with values predicted using the IESD model and results obtained from SAM.

\section{Methods}

\section{Wear trials}

The three firefighter suits studied were compact PVCcoated $(\mathrm{A}, 3.8 \mathrm{~kg})$, breathable $(\mathrm{B}, 3.0 \mathrm{~kg})$ and station wear $(\mathrm{C}, 1.8 \mathrm{~kg})$, worn over long-sleeved, polyester underwear. A total of 54 wear trials (six subjects with 
three repeats for each suit) consisting of $10 \mathrm{~min}$ sitting, 25 min walking $(5 \mathrm{~km} / \mathrm{h}), 10$ min sitting, 25 min walking and 20 min sitting were carried out at $30^{\circ} \mathrm{C}$ and $50 \%$ r.h. with a frontal wind of $2 \mathrm{~m} / \mathrm{s}$. During the last $15 \mathrm{~min}$ of each active phase of the wear trial, each suit was exposed to a frontal infrared (IR) radiation exposure of $500 \mathrm{~W} / \mathrm{m}^{2}$.

\section{SAM measurements}

The effective evaporative resistance of clothing is defined as:

$R_{\mathrm{e}, \mathrm{t}}=\left(P_{\mathrm{s}}-P_{\mathrm{a}}\right) \cdot Q_{\mathrm{e}}^{-1}$

where $\left(P_{\mathrm{s}}-P_{\mathrm{a}}\right)$ is the water vapour pressure gradient in $P_{\mathrm{a}}$ across the clothing and $Q_{\mathrm{e}}$ the evaporative heat flow in $\mathrm{W} / \mathrm{m}^{2}$ through the clothing. The intrinsic evaporative resistance $R_{\mathrm{e}, \mathrm{cl}}$ is calculated from $R_{\mathrm{e}, \mathrm{t}}$ using:

$R_{\mathrm{e}, \mathrm{cl}}=R_{\mathrm{e}, \mathrm{t}}-\left(R_{\mathrm{e}, \mathrm{a}} \cdot f_{\mathrm{cl}}^{-1}\right)$

where $R_{\mathrm{e}, \mathrm{a}}$ is the evaporative resistance of the unclothed manikin and the clothing area factor, $f_{\mathrm{cl}}$, is the ratio of the clothed compared to unclothed body surface.

Suits A to C were measured under conditions similar to the wear trials with SAM to determine the steadystate values of intrinsic dry thermal resistance $\left(I_{\mathrm{cl}}\right)$ and $R_{\text {e,cl }}$ with and without walking. These studies indicated that the effective insulation properties of clothing ensembles can vary significantly depending on the condition of body movement (Richards et al. 2003).

\section{Simulations}

Simulations were performed by modelling accurately the boundary conditions found in the experiments. This included detailed, ray-tracing-based modelling of the inhomogeneous IR irradiation at the individual surfaces of the exposed subjects (Ward and Shakespeare 1990; ThermoAnalytics 2001), and the use of measured clothing properties as time-dependent variables for the work and recovery phases of each wear trial.

Both the air and radiant temperatures of the climatic chamber were taken to be homogeneous at $30^{\circ} \mathrm{C}$. The air velocity was assumed to be constant at $2 \mathrm{~m} / \mathrm{s}$ from the front and $1 \mathrm{~m} / \mathrm{s}$ for the posterior parts, which was the average value measured at the back of SAM for the same frontal wind. As with the wear trials, an IR radiation exposure of $500 \mathrm{~W} / \mathrm{m}^{2}$ was defined for the last

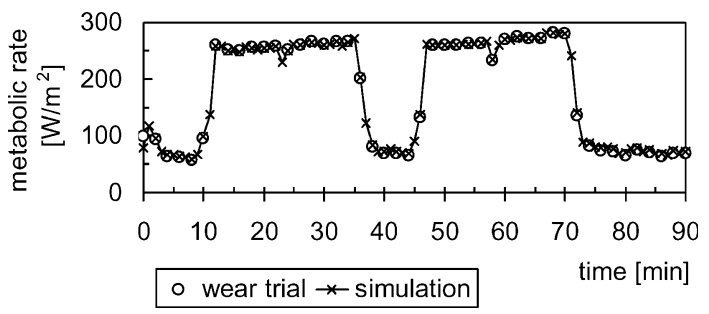

Fig. 1 Metabolic rates for wear trials and simulations for suit A. The lower and upper metabolic rates correspond to an oxygen consumption of about 0.26 and $1.291 / \mathrm{min}$ respectively, i.e. for an average young male when resting and exercising moderately

15 min of each active phase. Metabolic rates measured during the wear trials with an ergonometer were used as input for the IESD model, as shown for suit A in Fig. 1.

The individual clothing ensembles were modelled separately for 'still' and 'walking' conditions to obtain the same overall thermal and evaporative characteristics as measured by SAM. The overall $I_{\mathrm{cl}}$ values used were $0.146,0.214$ and $0.120 \mathrm{~m}^{2} \mathrm{~K} / \mathrm{W}$ for sitting phases and $0.117,0.155$ and $0.091 \mathrm{~m}^{2} \mathrm{~K} / \mathrm{W}$ for walking phases. The overall $R_{\mathrm{e}, \mathrm{cl}}$ values were 56,24 and $10 \mathrm{~m}^{2} \mathrm{~Pa} / \mathrm{W}$ for sitting and 27, 6 and $2 \mathrm{~m}^{2} \mathrm{~Pa} / \mathrm{W}$ for walking, for suits $\mathrm{A}$, $\mathrm{B}$ and $\mathrm{C}$ respectively. As in the wear trials, the underwear had long sleeves and long legs, with overall $I_{\mathrm{cl}}$ and $R_{\mathrm{e}, \mathrm{cl}}$ values $\left(0.105 \mathrm{~m}^{2} \mathrm{~K} / \mathrm{W}\right.$ and $\left.24 \mathrm{~m}^{2} \mathrm{~Pa} / \mathrm{W}\right)$ being added to the suit resistances in the simulations. The clothing area factors for the ensembles resulted in values of $1.3(\mathrm{~A}), 1.3(\mathrm{~B})$, and 1.25 (C), which were identical to the measured values. Local $I_{\mathrm{cl}}, R_{\mathrm{e}, \mathrm{cl}}$ and $f_{\mathrm{cl}}$ values were inferred from overall values using the steady-state approach for multi-layered ensembles proposed by McCullough et al. (1989).

The absorption of radiation at the clothing surfaces was modelled by considering the geometrical configuration of the wear trials, and calculating the required projected area factors for each of the 59 body sectors, with respect to both direct and diffuse IR radiation. The absorption coefficients of the suits were taken from measured spectral values as averages over the bandwidth of the emitter's characteristic irradiance, giving absorption coefficients of 0.315 (A), 0.930 (B) and 0.724 (C).

\section{Results}

Generally, the predictions fit favourably with the wear trial data. The deviations in temperatures are provided in the form of summary statistics using the root mean squared deviation (Fiala et al.2001) in Table 1.

Table 1 Root mean square deviations of predicted from observed temperatures in ${ }^{\circ} \mathrm{C}$

\begin{tabular}{lllllllllll}
\hline & Rectal & Mean skin & Chest & Back & Shoulder & Stomach & Upper leg & Lower leg & Upper arm & Lower arm \\
\hline Suit A & 0.26 & 0.38 & 0.80 & 0.57 & 0.69 & 0.79 & 0.66 & 0.52 & 1.04 & 0.31 \\
Suit B & 0.14 & 0.33 & 0.53 & 0.58 & 0.58 & 0.39 & 0.70 & 0.87 & 0.46 & 0.62 \\
Suit C & 0.11 & 0.28 & 1.21 & 0.83 & 0.57 & 0.21 & 0.46 & 0.45 & 0.62 & 0.79 \\
Under- wear & 0.12 & 0.39 & 0.63 & 1.01 & 1.44 & 0.33 & 0.53 & 0.72 & 0.35 & 0.43 \\
\hline
\end{tabular}


Figure 2 shows the rectal and mean skin temperatures measured during the wear trials with predicted values for suits $\mathrm{A}, \mathrm{B}, \mathrm{C}$ and the underwear alone, respectively. For the underwear and suit $\mathrm{C}$, the rectal temperature was reproduced very well. Good agreement is also seen for suits A and B up until the end of the second active phase, with noticeable discrepancies only occurring during the final rest phase $(t>70 \mathrm{~min})$ for suit $\mathrm{A}$.

Also, the mean skin temperature was reproduced well for all the clothing, considering the spread within the wear trial results. No significant discrepancies resulted either for temporal trends or absolute values.

Compared to the mean skin temperature, a lower level of agreement was obtained for local skin temperatures. As an example, the predicted and observed local skin temperatures for suit B are shown in Fig. 3.

The predicted total moisture loss (including expiration loss) during an exposure is compared with the corresponding measured values for ensembles $\mathrm{A}-\mathrm{C}$ in Table 2. The incorporated sweating model took into account the effect of sweat gland activity suppression with increased levels of skin wettedness; a phenomenon that was observed experimentally by Nadel and Stolwijk (1973).
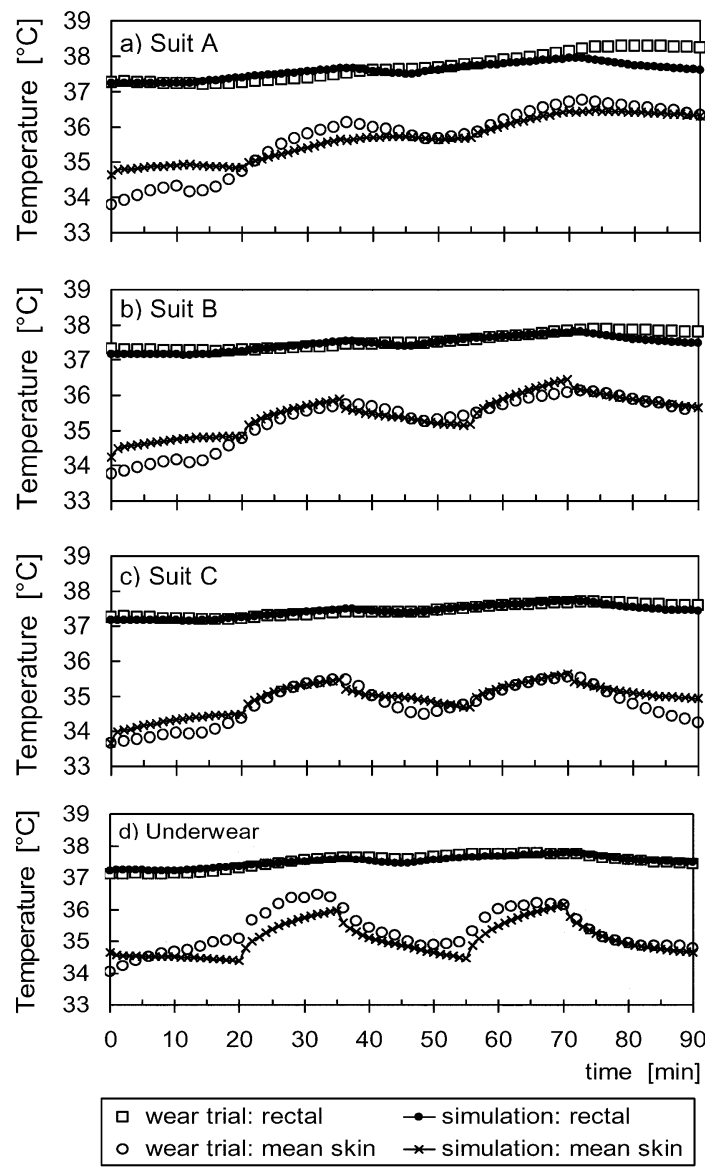

Fig. 2 Observed and predicted rectal and mean skin temperatures for suits $\mathrm{A}-\mathrm{C}$ and the long-sleeved underwear alone
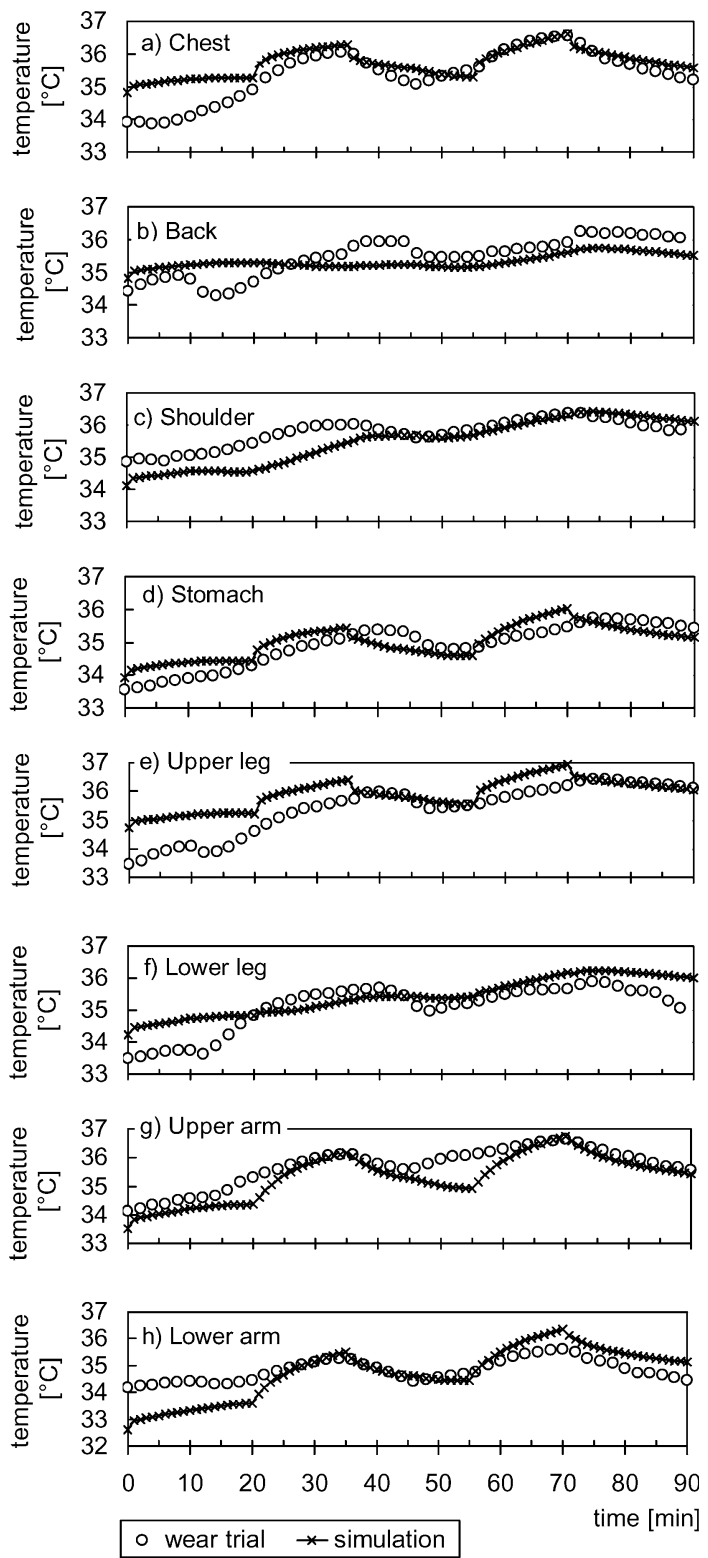

Fig. 3 Comparison of observed and predicted local skin temperature for suit $\mathrm{B}$

In Fig. 4, the observed partial vapour pressures between the underwear and suit $\mathrm{B}$ are compared with values calculated from predicted vapour pressures at the skin. For simplicity, the average $R_{\mathrm{e}, \mathrm{cl}}$ values for walking and rest were used throughout. As saturation was predicted for times greater than about $30 \mathrm{~min}$, the predicted

Table 2 Total moisture loss observed (SD) compared to simulation results

\begin{tabular}{lll}
\hline & Observed & Predicted \\
\hline Suit A & $1.5(0.2) \mathrm{kg}$ & $2.06 \mathrm{~kg}$ \\
Suit B & $1.2(0.2) \mathrm{kg}$ & $1.27 \mathrm{~kg}$ \\
Suit C & $0.92(0.15) \mathrm{kg}$ & $0.89 \mathrm{~kg}$ \\
\hline
\end{tabular}



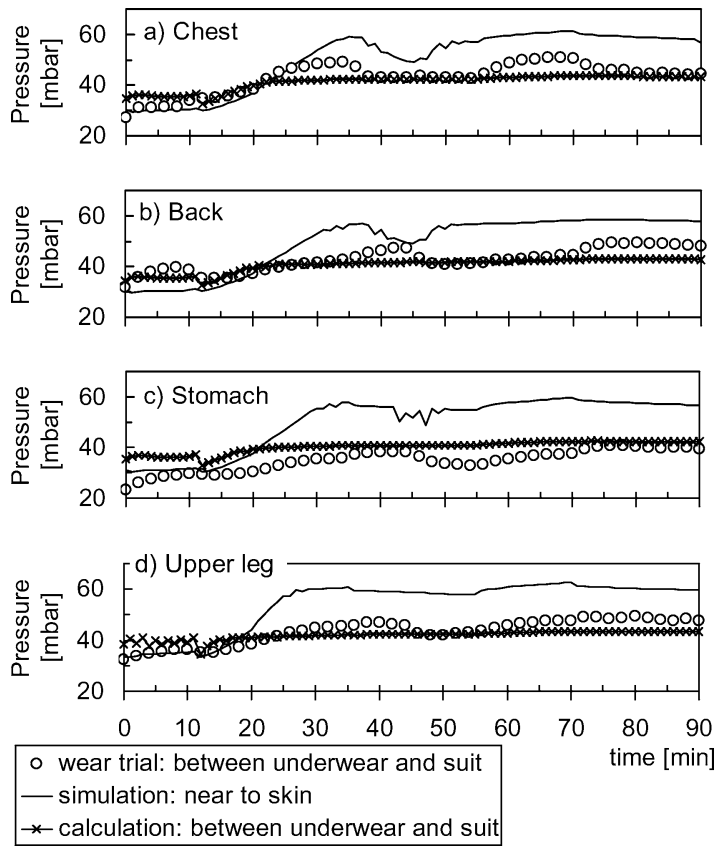

Fig. 4 Comparison of observed partial vapour pressures with those predicted and calculated for suit $\mathrm{B}$

and calculated values remain fairly constant. Nevertheless, the calculated values have a similar order of magnitude as those observed.

\section{Discussion}

The predicted physiological responses generally agreed well with the wear trial data. Simulations of the core and mean skin temperatures reproduced measured data, with root mean square (r.m.s.) deviations being typically lower than the experimental error. The local partial pressures predicted within the clothing systems had the right order of magnitude. Thus, in this study, the use of the IESD model, with detailed boundary-condition modelling and thermal and evaporative resistance for 'still' and 'walking' steady-state conditions obtained using SAM, appeared to be a valid approach. In future, however, a more rigorous consideration of the local microclimatic and heat transfer conditions within garments may become necessary. Moreover, simplified clothing models based on steady-state values of $I_{\mathrm{cl}}$ and $R_{\text {e,cl }}$ appear to be insufficient to simulate accurately the transient thermodynamic behaviour of clothing systems (Lotens1993).

As the segmentation of the IESD model is very similar to that of SAM, it is proposed to use the resultant local heat transfer coefficients measured underneath the clothing by each body section of SAM as input values for the model in future studies. Changes in the local $I_{\mathrm{cl}}$ and $R_{\mathrm{e}, \mathrm{cl}}$ values used, for example, will affect the local microclimatic conditions and local skin temperatures, as well as, to a certain degree, the overall responses of subjects.
A thorough analysis of the results indicated that the discrepancies between measured and predicted core temperatures after exercise were dependent on the evaporative resistance of the clothing, i.e. the discrepancies tended to disappear for small $R_{\mathrm{e}, \mathrm{cl}}$ values but rose with increasing $R_{\mathrm{e}, \mathrm{cl}}$. This observation suggests that these discrepancies seem to be due to the clothing model used. Possible dynamic effects relating to IR radiation that cannot be considered by a steady-state clothing model and could account for the reduced/delayed fall in core temperature following exercise are as follows:

1. Any radiant heat from the IR panel which is stored in the clothing hindered heat loss from the skin even after the source was switched off. The clothing could even have acted as a source of heat to the body after the panel was switched off (which coincides with the termination of exercise in the trials).

2. Furthermore, it is likely that the sweat moisture absorbed by the underwear also heated up. Particularly in the impermeable suit (A) there was a lot of excess moisture in the underwear capable of (i) storing heat and (ii) markedly changing the microclimatic conditions within the clothing. This may have led to high temperatures within the clothing and to vapour pressure profiles that are significantly different from any steady-state profiles/conditions. For such situations, static $I_{\mathrm{cl}}$ and $R_{\mathrm{e}, \mathrm{cl}}$ values are insufficiently applicable.

3. It is also conceivable that the hot vapour/steam in the trapped air condensed at the cooler skin, thus releasing additional heat to the skin and warming the blood. Further comparative work using a more sophisticated clothing model which takes into account these thermodynamic processes would certainly be of interest.

\section{References}

Fan J, Chen YS (2002) Measurement of clothing thermal insulation and moisture vapour resistance using a novel perspiring fabric thermal manikin. Meas Sci Technol 13:1115-1123

Fiala D, Lomas KJ, Stohrer M (1999) A computer model of human thermoregulation for a wide range of environmental conditions: the passive system. J Appl Physiol 87:1957-1972

Fiala D, Lomas KJ, Stohrer M (2001) Computer prediction of human thermoregulatory and temperature responses to a wide range of environmental conditions. Int J Biometeorol 45:143-159

Lotens WA (1993) Heat transfer from humans wearing clothing. Thesis, TNO Institute for Perception, Soesterberg, The Netherlands

McCullough EA, Jones BW, Tamura T (1989) A data base for determining the evaporative resistance of clothing. ASHRAE Trans 91:316-328

Nadel ER, Stolwijk JA (1973) Effect of skin wettedness on sweat gland response. J Appl Physiol 35: 689-694

Richards MGM (2000) Physiological studies of humans wearing fire fighter clothing systems for the validation of a sweating manikin. In: Werner J, Hexamer M (eds) ICEE 2000. Shaker, Aachen, pp 401-404

Richards MGM, Mattle NG (2001) A Sweating Agile thermal Manikin (SAM) developed to test complete clothing systems under normal and extreme conditions. In: Human factors and 
medicine panel symposium - blowing hot and cold: protecting against climatic extremes, vol4. RTO/NATO, Dresden, pp 1-7

Richards MGM, Mattle NG, Becker C (2003) Assessment of the protection and comfort of fire fighters' clothing using a sweating manikin. In: Mäkinen $\mathrm{H}$, Rossi $\mathrm{R}$ (eds) 2nd European Conference on Protective Clothing (ECPC) and NOKOBETEF 7, Montreaux, Switzerland

ThermoAnalytics (2001) Evaluation of the heat transfer mechanisms from RadTherm Technical Documentation, Calumet, Mich., pp 16-26
Tikuisis P (2000) Functional modeling in human thermoregulation to thermal stress. In: Werner J, Hexamer M (eds) Proceedings of the 9th international conference on environmental ergonomics, vol 7. Shaker, Dortmund, pp 375-380

Ward G, Shakespeare R (1990) Deterministic and Stochastic Ray Tracing. In: Rendering with radiance - the art and science of lighting visualisation. Morgan Kaufmann, San Francisco, pp 491-521 